\title{
Cycles of Innovation and Alignment in Digital Transformation: Investigating the Dynamics of Resource Recombination in a Construction Firm
}

\author{
Oscar Lundberg \\ Umeå University, Sweden \\ oscar.lundberg@umu.se
}

\author{
Johan Sandberg \\ Umeå University, Sweden \\ johan.sandberg@umu.se
}

\author{
Daniel Nylén \\ Umeå University, Sweden \\ daniel.nylen@umu.se
}

\begin{abstract}
The generative nature of digital technology implies that during digital transformation (DT), organizations traverse multiple cycles of innovation and resource alignment. Still, extant research mainly chronicles DT as linear and contained phenomenon occurring in response to a dramatic environmental change event. How new resources align with previous ones into novel combinations, the work that supports continuous organizational capability building, and the temporal relationships between cycles of change in DT has received scant attention. Drawing on dynamic capability theory, we analyze innovation and resource alignment cycles driving DT at Lundqvist Trävaru AB, a small Swedish construction firm. Our study has at least two contributions. First, the analysis reveals three types of dynamic capabilities that shape resource generation and alignment in DT. Second, we provide a process model outlining the innovation and alignment cycles that fuel DT as they scale in the focal firm.
\end{abstract}

\section{Introduction}

Contemporary firms are making substantial efforts to digitize products, services, and processes [36], creating new digital business models [2] and reformulating business strategies for the digital era [6]. Since digital resources and their applications continuously evolve and create turbulent environments [13], managing such changes is a delicate task. The notion of digital transformation (DT) encapsulates this wide array of digitally driven changes. Lately, it has become a critical topic in both practice-oriented discourses and Information Systems (IS) research.

Digital innovation processes fuel DT by generating new digital resources and novel resource combinations [17]. Digital resources are "entities that serve as building blocks in the creation and capture of value from information in digital innovation" [17:92]. In contrast to non-digital resources, digital resources are programmable, distributable, and accessible [39] to provide information, communication, and connectivity values [6]. Hence, digital resources are not selfcontained units with fixed meanings and relations. Instead, they are loosely coupled and combinatory, whereby firms can apply their capabilities to leverage multiple value paths through design and use combinations [17].

An important, but largely neglected, issue in DT is the alignment processes in which new (digital) and existing resources are integrated into novel combinations [33]. Alignment between firms and the competitive landscape in DT processes has received substantial interest. However, IS research on DT has mainly focused on the input and output of the transformation [5, 27]. Thus, we are only starting to grasp how such processes unfold within firms, and the patterns of interdependent actions that underlie them [14]. Investigations of the DT process are scowl and lack longitudinal accounts [10,33]. IS research has paid substantial attention to the nature of fundamental elements of DT (i.e., IT-enabled transformation, digital innovation, and service innovation) and their immediate relationships. Yet, outcomes of their interactions are complex and not necessarily well understood through analyzes of short-term effects [25]. Instead, we argue that DT transpires through multiple digital innovations whose outcomes need to be aligned, combined, and work in symbiosis over time. To understand the interdependencies between such events, we argue that a longitudinal perspective is crucial.

Based on an extensive literature review, Vial [33] presents an inductively generated framework of DT. He argues that "digital technologies play a central role in the creation as well as the reinforcement of disruptions taking place at the society and industry levels" [33:5]. Thus, development of digital resources creates exogenous forces that push firms to change by fueling and enabling disruptions. However, it is through endogenous processes that firm-level DT occurs. Accordingly, analyses of how DT unfolds need to consider the alignment of existing resources with new (digital) ones that generate novel combinations 
and capabilities. To increase our understanding of this endogenous driver of DT, we explore the question: "How can organizations align new (digital) and existing resources into novel combinations, and how do such processes fuel digital transformation over time?"

We conducted a longitudinal case study of a small construction firm, Lundqvist Trävaru $A B$ that transformed from a pure product-centric firm to an active participant in a business ecosystem enabled by digital resources. We examine antecedent change explaining how a small construction firm in a sparsely populated area and with little digital competency came to develop an award-winning digital innovation, the Web-based 3D Configurator (W3DC) (available at https://www.lundqvisttravaru.se/), and transform their value creation process. To understand this process, we draw on theory on dynamic capabilities (DC) [28, 29, 37]. The DC lens enables specific consideration of organizational actions to reconfigure resources in response to changing environments $[12,30]$.

Our analysis reveals a path dependent and cumulative pattern in the DT process across three cycles with an increasing scope of change; digitizing a task, digitalizing processes, and transforming the value creation system. We inductively identified opportunity recognition as a contextual trigger for three DC enabling changes in the value creation path: Scanning resources, designing combinations, and evaluating outcomes. Grounded in our analysis, we provide a process model of such cycles of alignment and innovation fueling DT as it increases in scope.

\section{Theoretical Foundation}

\subsection{Digital Transformation}

Researchers have developed various definitions of DT [33:4]. In this paper, DT is understood as "the combined effects of several digital innovations bringing about novel actors (and actor constellations), structures, practices, values, and beliefs that change, threaten, replace or complement existing rules of the game within organizations, ecosystems, industries or fields" [18:53]. Due to its significant effects on organizational elements, DT is a complex and longterm process, including several management dilemmas $[5,15,20,27]$.

DT is driven by digital innovation, i.e., the combination of physical and digital resources to produce novel products or services [22, 23, 39]. The combined effects of such innovations fuel transformative processes. Thus, DT requires significant changes in firm structures [33]. Firms' existing purpose, boundaries, and activities [32] may, over time, be threatened, replaced, or complemented. As firms are rather pushed towards an ecosystem logic [18], DT includes and affects more actors, processes, artifacts in extended networks or ecosystems than traditional IT-enabled change projects [27, 33]. While such scope extensions and decreased control over change increase complexity, a greater variety of actors can contribute and exchange resources, and therefore combine vital outputs in the value creation process [1].

IS research typically characterizes DT as the outcome of radical innovations by firms in digitalization's frontline. These firms provide novel values by successfully utilizing digitally enabled potentials, making them part of multiple value paths [17], which may disrupt markets. Triggered by exogenous change, other firms need to develop strategic responses [33] which entail finding novel ways of aligning these digital innovations with their business to cultivate new value creation paths. Achieving such alignment is complex [25], since firms never start their DT journey from zero [4]. Existing (and often stable) structures, resources, and capabilities need to be continuously renewed and exploited to be digitally reverted [29].

Results of prior digital innovations enable a new set of "conditions" that foster distinct opportunities for further digital innovation [16]. Thus, DT is a continuous process based on several digital innovations that build upon each other to reach transformative scale. This continuous process is not limited to integrating various digital resources - it includes adapting organizational management $[15,27]$ of cultural, technical and individual barriers [34], capability building processes [20, 29], and alignment of novel and existing resources. Effectively combining existing digital and non-digital resources is therefore critical for achieving successful DT. Thus, more research is needed on how such endogenous change processes occur in, and enable DT.

In this line of argumentation, Skog [27] claims that firms engaging in DT should not only focus on producing innovations, but also generate abilities to exploit opportunities and adapt over time. These organizational abilities are about "sense disruptions, seize them (e.g., through strategic responses) and to reconfigure elements of their business model accordingly" [33:16]. However, how such alignment unfolds in practice is not well-known. Particularly, we lack micro-level analyses of practices and activities that undergird the DT process. Therefore, Besson and Rowe [5] suggest that researchers should describe and conceptualize the process of transformation instead of its value creation outcome. In addressing these issues, we respond to Vial's suggested research agenda 
regarding the "Micro-foundations of dynamic capabilities: how digital transformation unfolds in practice" [33:17].

\subsection{Dynamic capabilities in digital transformation}

The notion of dynamic capabilities (DC) is rooted in the resource-based view (RBV). RBV emphasizes firms' specific resources and capabilities as the fundamental causes of firm performance [30]. To better account for the dynamic shifting relations in organizational environments, the notion of combining resources was introduced in DC: "The competitive advantage of firms is seen as resting on distinctive processes (ways of coordinating and combining), shaped by the firm's (specific) asset positions (such as the firm's path(s) it has adopted or inherited" [30:509]. The most widely cited definition of DC comes from Teece et al., [30]: "the firm's ability to integrate, build, and reconfigure internal and external competencies to address rapidly changing environments" [30:515].

A relative amount of literature draws on DC theory to explore constitutive elements of DT. However, research on DC building in relation to DT remains scarce $[19,33]$, with some noticeable exceptions. First, $\mathrm{Li}$ et al., [20] demonstrated that successful DT initiatives by entrepreneurs in SME's entail far more than just embracing digital technology. Entrepreneurs need to engage in both managerial and organizational capabilities building. Second, Gao et al., [15] identified a lack of DC as an inhibitor of change in the metal and mining industries. These findings suggest that increased attention should be paid to "how, when, and why organizations reconfigure their resource and capability base when confronted with technological disruption and - vice versa - how innovative technologies enable new dynamic capabilities" [19:4712].

In essence, DC enables an analysis of how organizations cope with dynamic and shifting relations in their environment $[12,30]-\mathrm{a}$ characterizing aspect of DT. Indeed, Vial's [33] extensive literature review on DT reinforces this argument, calling for research into how DT unfolds, and what role the underlying capabilities and micro-foundations have in that process. Responding to this call, we draw on DC three broad capabilities; sensing, seizing, and transforming $[28,29]$. We, in this way, conceptualize DC scope in tandem with the DT literature. We next define and explain each of the three activities in turn:

Sensing refers to the firm's activities to identify opportunities [28, 29]. In the context of DT, this involves capabilities for scanning the market [37]; i.e., which digital resources do customers and other firms use? How can these opportunities be made accessible and attractive? Thus, continuously evaluating the firm's environmental fit and needs to manage disruptive change [33], environmental turbulence [13], and sensing opportunities from prior digital innovations become critical concerns $[16,18]$.

Seizing includes the firm's activities to mobilize resources to address the sensed opportunities [28] and "capture value from doing so" [29:18]. In DT, this means turning the new digital resources into digital capabilities [24] by combining existing digital and nondigital resources (partly generated from prior digital innovations) with new ones. Further, firms need to create conditions to operationalize and strategize them both inside and outside of the firm to permit new value paths $[3,6,21]$.

Transforming describes the firm's activities to (re)align and continuously renew the captured state $[28,29]$ in order to, in turn, avoid resource misalignment [10]. In DT, this activity includes implementing the new strategy. The firm, therefore, needs to align the new resources with existing organizational structure (e.g., routines, rules, values) [37] through constantly testing and combining with other resources due to the continuously shifting and evolving environment [27].

In contrast to Yeow et al.'s [37] rigorous study of strategic alignment, this study explores the microdynamics of DT, including the endogenous change that triggers and enables DT. We draw on these sensitizing concepts [8] to investigate the underlying microfoundations in digital innovations and resource alignment that foster DT.

\section{Research Design}

Drawing on an interpretative approach [35], we conducted a longitudinal case study [38] of Lundqvist Trävaru $A B$ - a family-owned construction firm founded in 1936. In the beginning, Lundqvist was principally a furniture joinery, acting as a subcontractor to the Swedish defense. Today, the firm has around 30 employees, and produces, sells, and delivers building kits for garages, cottages, stables, carports, machine halls, and villas. It does so by utilizing a digital service - a Web-based $3 D$ Configurator (W3DC). The W3DC is the centerpiece of Lundqvist's website, and allows customers to design and order buildings. Lundqvist has received several awards for this innovative service, including the Swedish Digital Gazelle in 2014 (given by Google and Dagens Industri, the largest daily business newspaper in Sweden), Entrepreneur of the year in 2016 (given by 
Ernst and Young), and Smart industry 2018 (given by the Royal Engineering Academy).

Given Lundqvist's remote geographical location and deep physical anchoring, the emergence and success of the W3DC was unexpected. The firm operates in a conservative and traditional productbased industry characterized by slow adaption and development of digital innovations $[11,26]$. Therefore, the surprising generation of an award-winning digital innovation offered a compelling opportunity for theory generation.

We collected rich data regarding historical and current change at Lundqvist from four primary sources: Online data, semi-structured interviews, unstructured interviews, and observations. Our data collection started with a review of relevant online data. The review resulted in 122 Facebook posts, 36 news posts, and 37 press releases from the period between March 2010 to October 2018. Secondly, we visited the firm on two separate occasions, totaling at six full days. We conducted 14 semi-structured interviews and five unstructured interviews with an array of professional roles, including CEO, COO, Senior advisor, System developer, Design engineer, Production preparation manager, Sales manager, Production manager, Sales rep, and Carpenter. The semi-structured interviews were audio recorded and transcribed. Extensive notes were taken during the unstructured interviews. The average interview lasted 40,5 minutes. Between interviews, we observed production, sales, and logistics procedures, and witnessed demonstrations of Lundqvist's digital systems. These observations resulted in 20 pages of field notes.

An inductive approach directed our data analysis. We first examined the online data, looking to identify key events in Lundqvist's DT process. Rather than seeking to understand these events in depth at this point, we created a visual timeline outlining their temporal order [31]. The timeline was used as guidance to next delve deeper into how resources were generated, aligned, and combined during the DT process by analyzing the interviews using Braun and Clarke's [9] thematic approach. The objective was to find and describe patterns across the process.

First, we familiarized ourselves with the interview data by importing the transcripts to QDR-miner to perform initial coding. We strived to be open and responsive to the data, rather than imposing theory informed preconceptions [9]. Second, we reviewed our 241 initial codes, merging and recoding them. Third, after 95 stable codes were developed, we searched for themes describing a broader set of codes. We triangulated the data, iterated, and evaluated the properties and meaning of the codes in relation to the timeline [9]. We ended up with three themes describing a path dependent and cumulative pattern in the DT process across three cycles characterized by an increasing scope of change: digitizing a task, digitalizing processes, and transforming the value creation system. Fourth, we reviewed relevant literature and found apparent links to the sensitizing concepts from the dynamic capability (DC) literature. Applying an integrative approach, we allowed the identified themes to be reflected against these sensitizing concepts as well as the DT literature. In each cycle, we identified opportunity recognition as a triggering condition for activation of three recurrent capabilities: Scanning resources, designing combinations, and evaluating outcomes generating a new value creation path. Lastly, we developed a process model (Figure 1), explaining the relationship between conditions, triggers, and capabilities, realizing a resource alignment cycle.

\section{Findings}

\subsection{Cycle 1: Digitizing a task (2000-2004)}

Lundqvist's DT efforts can be traced back to the late 1990s and the commercialization of the Internet. By accident, CEO 1 (who is currently a Senior advisor) identified a new production technique. It entailed standardizing Lundqvist's products according to a block system, dictating that every building block should be 1.2 meters wide. This system facilitated a radically increased economy of scale. Notably, several respondents also describe the block system as a primer for DT at Lundqvist:

"To me, the [block] system was actually the core of our ability to digitalize. Too often, people focus on digitalization as such. But really, you need to consider the business, the products, or the services, and assess whether it is [relevant] to digitalize it." (COO).

Having increased internal efficiency, CEO 1 next explored possibilities to increase and diversify the customer base. Previously, Lundqvist mainly found their predominantly local customers through word-ofmouth (opportunity recognition through innovation exploration). Therefore, CEO 1 started scanning the environment for available marketing resources. However, at that time, advertising was costly:

"I started to place advertisements, but that was almost before the Internet [...] I could not afford Vi $i$ Villa [Sweden's largest magazine about houses], which would almost cost me a full month's salary. But then $P C$ 's started emerging, and I started playing around in [Microsoft] Office [...] creating a little price list based on sizes and everything. Then suddenly someone from southern Sweden called me up, and even more phone 
calls started coming in. Half of my working day was spent talking on the phone to first understand what they were after, and next calculate a price based on the length and width." (CEO 1).

He recognized the potential of exploiting digital resources for marketing, and by scanning competitors' digital marketing efforts and exploring the Internet's capabilities, he found several options (scanning resources). Finally, he decided to use Microsoft FrontPage to build the first Lundqvist-website. Using his paper-based block system documentation, he keyed the measurements into FrontPage's document manager (similar to Excel), creating scripts which could perform basic calculations. A simple drop-down allowed the customers to enter the desired width and length of their building, and thereby receive an approximate price (designing combinations).

The website was a success. More customers started to call Lundqvist to order buildings. However, the website also caused an uncontrollable amount of customer orders. Thus, the website triggered a new need to pursue additional resource combinations for managing customer orders. CEO 1 further explored the MS Office-suite, and by combining the block system data from Frontpage with Excel, he created an Access database for storing and saving customers typical selections of building kits (several building blocks that constitute a building). Each customer's specific choice of additional items (i.e., door, window, roof) was recorded through phone calls and later saved in the database (evaluating outcomes). CEO 1 explains:

"I wasn't knowledgeable in computers at all. And how many nights I spent... Christmas holidays I would sit there building, and building. [To me] it was like a computer game: I read up on [and created] loads of [mathematical] formulas. I [continued] to build and build and then finally after a few months, [when] customers called and asked, "what does this size [of a building] cost", I could answer them directly."

While the new website was an effective marketing channel, Lundqvist needed additional resources to manage customer orders. The new access database generated direct values; more efficient customer order management, as well as indirect values; customers could enter width and length on the building blocks on the website, and retrieve answers faster through phone calls with Lundqvist's help, based on the automatized Excel calculations (value creation path).

\subsection{Cycle 2: Digitalizing processes (2005-2009)}

In 2004, a fire destroyed most of the Lundqvist's material resources, triggering a significant change in the resource establishment process. In addition to rebuilding physical resources (i.e., facilities, machines, tools), Lundqvist hired four new human resources. Two were technical sales reps who would come to play critical roles in Lundqvist's DT process, and transition into the roles as CEO 2 and COO.

When the COO assumed duties as a technical sales rep, he discovered that the digital resources utilized were misaligned. Particularly, the access database lacked structure and was extremely time-consuming to use (opportunity recognition from firm misalignment). Instead of immediately incrementally improving the database, he and CEO 2 scanned the firm's internal environment to understand perceived needs, intending to increase confidence and create a more open organizational culture. The goal was to redesign the database to better support work routines (scanning resources). This internal scanning was a critical activity for Lundqvist's continued DT process:

"I knew that the staff were sitting on great ideas on how to improve their own work routines. I tried to retrieve these ideas from them but they had given up. They felt that there was no reason to come up with ideas, as nothing would be changed anyway. [...] So, I decided [...] to take every opportunity to show what I'm made of in order to create trust. It was stuff like "the coffee tastes bad", or "we have too few hammers". I tried to solve all of these everyday micro-problems. And of course, if you think about it - if the staff don't believe that we can solve the coffee problem, of course [they won't believe that] we can make the big improvements either. But slowly, we built trust, and the staff began to share the great ideas [...] which resulted in us becoming more efficient, and we started to grow". (CEO 2)

With CEO 2 and the $\mathrm{COO}$ as a driving force, existing human resources were recombined internally to develop a common culture (designing combinations). Several respondents stress that currently, Lundqvist deviates significantly from the typical construction industry business culture. The production preparation manager explains:

"We have had sort of a digitization philosophy: Everything does not have work perfectly [...] at all stages [...] as long as the system supports a majority of the work in a rapid and efficient manner. [Why] we are doing well is because we are able to adapt quickly, and build [digital] systems."

CEO 2 describes the new organizational culture as a "gold mine," characterized not only by an adaptive mindset but also by efficient utilization of new resources. Employees started to share their ideas on how to pursue incremental changes in the access database.

Through this cultural change Lundqvist shifted its identity from a traditional construction firm to defining itself as a technology, logistics, and sales firm. 
Furthermore, transformative efforts were no longer limited to the production process: Lundqvist now sought to digitalize other links in its internal value chain, including sales, production preparation, engineering, and administrative processes. Therefore, Lundqvist conducted several incremental improvements, such as redesigning and migrating the access database to cloud services (mainly google drive) (evaluating outcomes).

The updated database made it easier for employees to access, create, save, and print customer orders. It also provided smoother access to planning lists and material lists for each building in the production pipeline. These efforts resulted in what our respondents refer to as the small-block-system. This system follows the previous block system's 1.2-meter standards, but has automatic features supporting an array of core business processes including sales, planning, drawing, and calculation of complementary buildings, (i.e., cottages, garages, machine halls) (value creation path). These efforts served as a fundamental basis for next engaging in more radical and innovative DT efforts.

\subsection{Cycle 3: Transforming the value creation system (2010-2018)}

In late 2010, a new opportunity for innovation was identified based on three core realizations. First, the access database contained large amounts of valuable data for innovation exploration. Second, employees worked according to standardized processes. Third, the environment had changed in that customers now demanded more dynamic and visual product information (opportunity recognition based on innovation exploration and environmental change). Management explored potential resources to be leveraged to exploit existing data and satisfy this particular customer need. In scanning the market, IKEA and computer game The Sims stood out as inspirational examples, igniting an idea to create a Web-based $3 D$ Configurator (W3DC):

"[Our] gaming interest has made us naive and curious as to what we believe can be accomplished. [...] [Managers in] our generation won't say: "Let's digitize our business." We live around it, it's just an extended arm, nothing new. It's about being a bit smarter, utilizing tools that simplify things [...] No one will ever ask us; "how come you decide to go for nail guns instead of ordinary hammers." It's just a tool that makes things smoother." (COO).

In the resource exploration-phase of the W3DC, management realized that the project was too advanced to realize by exclusively utilizing their existing resource portfolio; they needed to acquire coding expertise. Lundqvist initially explored how such knowledge could be obtained, both through online courses, and by pitching the concept to IT-consultancy firms to get quotes. At the time, however, Lundqvist did not have the time or monetary means required for such outsourcing. Therefore, the firm started reaching out to universities, mainly by putting up posters in neighboring town's campuses (scanning resources). CEO 2 explains the importance of this activity:

"We had so many ideas [...] Many firms, especially SME's, have the problem of being "too much into the daily work." [...] We [are] always wondering how we can create more time. Here the contact with the university was crucial for us. The university turned out pretty early to be our external development department."

In early 2012, Lundqvist ran into a game design student looking for a case for his bachelor degree project. It decided to give the student a chance, and soon realized he had the skills required to realize the W3DC. In particular, it became evident both what was possible, and how complicated things really were.

Upon completing his degree project, the student entered a full-time developer position at Lundqvist. The design of the W3DC took off at a rapid pace. In addition to the access database, management had prepared a list of requirements for the W3DC, which highly emphasized the user perspective (customers and employees), and a storyboard outlining key steps in the user journey. A project group was formed including management (the $\mathrm{CEO}, \mathrm{COO}$, and a manager), and the developer. Management contributed knowledge on firm procedures, designing thoughts and requirements, and the developer was responsible for materializing these concepts.

The purpose of the W3DC was enabling customers to, after entering the Lundqvist website, design their own building through choosing from multiple options of available components, products, and services (e.g., doors, windows, color, transportation, mounting). Based on their specific choices, an interactive price calculator provides an approximate price. When customers are satisfied with their design, they submit an HTML-link pointing to their W3DC-generated sketch to Lundqvist's sales department through an integrated e-mail function (designing combinations). The production preparation manager explains the purpose of the W3DC:

"Let us say you went to a [online] clothing store. No colors or sizes exist, so you have to call them and ask. That little extra step alone, may turn people who are looking for simpler shops away. The more technology evolves, the more people expect things to be simple."

Traversing the design process, the project team sensed that fulfilling customer needs were relatively 
straightforward. However, deficiencies were revealed when testing the W3DC with employees. The project group evaluated these deficiencies and realized that several additional capabilities were needed to support internal work procedures fully. Therefore, it decided on designing a separate internal IT-system (the Lundqvist Portal). The central component of the portal was an interface enabling seamless interaction with the access database and the W3DC. The portal primarily functioned as a traditional ERP/CRM-system, but was based on the small-block-system logic. In this way, employees could utilize what customers had designed themselves in the W3DC (evaluating outcomes).

CEO 2 describes the portal as a "bridge" between Lundqvist's internal and outward facing IT-systems. In turn, the system developer describes the W3DC as the "visual innovation - what the market and industry saw." Meanwhile, he argues that the Lundqvist portal was the critical resource for actually utilizing the W3DC's capabilities internally:

"Well, if we focus exclusively on the W3DC, the routines have changed a lot. However, I am also thinking about the internal [IT-system]. The employees do not have to perform all the tasks they used to. The documents will now be printed out automatically, which frees up more time so that the employees can become more effective."

The combination of the W3DC and the portal had substantial transformative effects on Lundqvist's business. They had gone from digitizing a task, via digitalizing processes, to leveraging digitalization to expand customers' roles as contributors of resources in the overall value creation process. The sales manager explains how the value creation process now starts with customers using the W3DC to design their building (thereby generating data that can be made visible and accessible for Lundqvist employees). The portal automatically retrieves the HTML-link pointing to the customer's design, and transforms it into a standard quote, which is later e-mailed back to the customer. The sales manager describes the advantages of combining the W3DC and the portal in this way:

"The calculator [W3DC] has a combined interface through which all data can be retrieved by a few keystrokes. [As a sales rep] you don't have to sit around with a calculator and add, multiply, subtract etc. [...] Rather you can devote all your time to serving customers, [providing] them answers they need urgently. [...] Today, producing a standard quote takes 5 minutes. It used to take 30 minutes."

By 2014, Lundqvist had transformed its business in a way that affected both its customers and sales team. In addition to being utilized by the sales department, the data generated by customers using the W3DC was also used by Lundqvist's engineers and production staff for doing calculations and preparing material lists for the firm's production system. However, the DT process did not halt: The COO explains how Lundqvist also redirected its collaborations with subcontractors. For example, the logistics partner can now access specific modules of the portal to continuously monitor Lundqvist's production pipeline in order to assess and plan the transportation resources required over the coming months (value creation path).

What had started as an isolated effort to digitize a specific task was now a fundamentally transformed value constellation, including customers and subcontractors. The new value creation path has already fostered several new opportunity recognitions (e.g., developing and licensing a W3DC for a bathroom furnishing firm, and the opening up of additional modules in the portal for other partners (opportunity recognition through innovation exploration).

\section{Discussion and Conclusions}

Extant research provides substantial insights into the disruption of markets through radical digital innovations and on the input and output of DT processes [5, 27]. However, there is a scarcity of longitudinal studies $[10,33]$ investigating the underlying remolding of resource combinations and organizational capabilities in DT $[19,20]$. We contribute in two regards by offering a detailed and microlevel analysis of how the DT process can unfold in practice [33]. First, we provide a process model (Figure 1) explicating innovation-alignment cycles in which new (digital) and existing resource are fused into novel combinations [33]. The model provides a theoretical account of how DT is fueled by cycles of digital innovation and resource alignment. Second, we contribute with an empirically grounded account of how such processes unfold and grow in scope (task, process, and value creation system).

We propose a process model (see Figure 1) that emphasizes the contextual trigger (a) opportunity recognition that activities (b) dynamic capabilities (DC) prompting new resource combinations involving digital technologies which generate a new (c) value creation path. Over time, the use of novel resource combinations fosters a new opportunity recognition.

Opportunity recognition. Our study demonstrates that realizations of inadequate performance are essential triggers of shifts in the value creation path. We identified three distinct triggers; firm misalignment, environmental change, and innovation exploration. For example, in cycle one, the positive experiences form the introduction of a new resource 


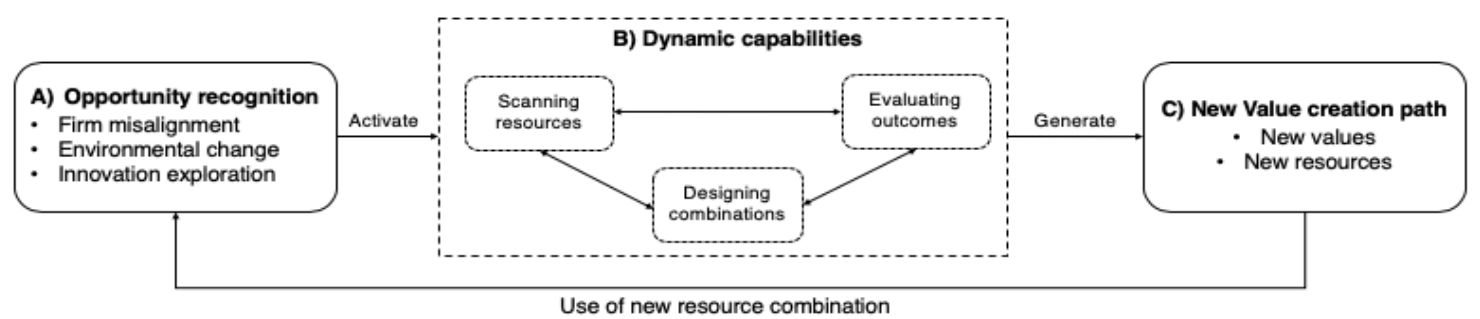

Figure 1. A process model of digital innovation and resource alignment in DT

(the block system) generated further interest in exploring opportunities to market products in new ways (innovation exploration). In contrast, in cycle two, identifications of problems and constraints in the access database activated the DC (firm misalignment). In cycle three, several triggers interacted: First, Lundqvist realized that existing manually generated data and customizable work process could be leveraged (innovation exploration). Second, customers expected better and more accessible information on products and services through the web (environmental change). Thus, triggers of opportunity recognition are contextually dependent and change over time as the market evolves, distinct resource combinations are in use, and organizational experiences develop. However, in each cycle, opportunity recognition activated the three DC shaping novel resource combinations.

$D C$. Our inductive study revealed three DC [28, 29, 37], mainly activated in the exploration/construction phase of DT [5]; scanning resources, designing combinations, and evaluating outcomes. These three capabilities were the driving forces that enabled Lundqvist to take advantage of the opportunity recognition. As the organizational system in which they were activated and the resources on which they acted evolved between cycles, these capabilities also played out differently and varied in scale and scope between cycles.

Scanning resources. The scanning capability captures the activities related to exploring resources $[29,37]$. It includes both scanning the internal environment (what resources do we have, and what resources do we need?) and external environment (what resources does other use?). For Lundqvist, the scanning activity often resulted in organizational learning [28, 29] through inspiration on resource generation and ideas for the development of novel combinations. For example, when the idea for the W3DC emerged, Lundqvist scanned resources at several different places (online, other firms, ITconsultants, and universities). Scanning resources is the first step towards a commitment of change for responding to the opportunity recognition.

Designing combinations. The second DC builds on output from scanning as a commitment to a resource arises. Designing combinations refer to the activity where the firm invests in the identified new resources and starts to implement, design, and combine them with the existing [37]. For Lundqvist, these activities included combining the new resource though extending the available, recombination's of existing resources, and design and use combinations utilizing digital resources [17].

Evaluating outcomes. The third DC is activated when tentative outcomes are available. Evaluating outcomes refers to as the activity where firms test the new resource combination in regards to interactions with other operational resources and fit with the firm structure [37]. These activities are similar to what Teece refers to as transforming, continuous renewal including "asset alignment, co-alignment, realignment, and redeployment" [28:1336]. However, the malleability of digital resources [39] enables such activities to occur faster, more often, and for extended periods, even after implementation [22]. We suggest that evaluating outcomes capability is generated by repeatedly testing and launching reaction processes that reactivate capabilities for scanning resources and designing combinations. The reaction processes trigger an exploration of options for design combinations and incremental changes in existing and new resources to identify successful alignment alternatives. (This is why the arrows between the DCs in the process model are bidirectional). For instance, the massive amount of phone calls from customers due to the effective website marketing surprised Lundqvist. To adapt, they needed to engage in further activities to scan new resources, recombine, and test. In innovation cycle three, however, Lundqvist initiated tests of the W3DC internally with the existing routines and available resources. Thus, found constraints, and after that initiated new design combinations.

Value creation path. The outcome of innovation and alignment activities realizes new use of (digital) resources in a novel value creation path, also referred to as the stabilization/institutionalization phase [5]. The new path is, however temporary, as the novel resources combinations over time foster distinct use patterns and further exploration of innovation possibilities. In this sense, the new state enables another innovation and alignment cycle. 
In essence, the model indicates a longitudinal and iterative process between organizational conditions that trigger, and recursive DC that shape resource alignment process in DT. These findings suggest that firms who recently have realized a new value creation path can capture momentum and explore new opportunities. These results emphasize that DT is a continuous and cumulative process [20, 27, 33] and that prior digital innovation enables a new set of conditions for further digital innovations [16]. Over time, combinations of these innovation and alignment cycles may realize transformative effects [18].

Our study has several practical and theoretical implications. First, we demonstrate that endogenous DT emerges in a path-dependent and cumulative process based on 'wakes of innovation' [7] that foster opportunities for new novel resource combinations facilitating DT. At Lundqvist, the DT process unfolded in three innovation cycles with a distinct scope of change. Digitizing a task included minor change and mainly focused on moving on a specific task. Digitalizing processes emerged as an expansion of several digitized tasks that works in a process. Transforming the value creation system resulted in a fully digitalized value chain, where more or less all processes were digitalized, including key transactions with external actors.

Second, our findings suggest that DT processes are likely to scale through several innovation cycles. At Lundqvist, each cycle set the stage for growth in scope in the following one by contributing with new resources, organizational learning, and capability building processes. Capabilities that seem irrelevant at the time they are used (i.e., digitizing a task), may in a later stage be critical for the DT process to continue evolving. At an aggregated level, Hinings et al., [18] argue that such path dependencies involve the act of combining several digital innovations to reach transformative scale. We extend this argument by emphasizing the role of the process of generating each digital innovation for capability building. To spur such processes, firms should consider engaging in multiple smaller digital innovation projects in order to facilitate learning cycles.

Third, DT requires managerial awareness of the path dependencies between the multiple cycles of innovation and alignment [18]. Organizational learning and DC building processes occurring in each cycle are critical for aligning each innovation and combine its effects in DT. These organizational learning and capability building processes are essential enablers for firms engaging in DT processes. We provide empirical evidence for how DC acts as "the engine" in realization of new value creation paths $[1,28,29]$, which in turn constitutes the breeding ground to launch further innovation cycles.

Gao et al. [15: 4933] argue that "if the historical rate of systematic change in an industry is low, firms lose their dynamic capabilities to change". In contrast, our study shows how a firm in a traditional industry with a historical record of low digital innovation engagement could nevertheless maintain and further develop its DC. Lundqvist's DC building was not only triggered by environmental change; instead, endogenous triggers were prominent. Hence, firms should not only consider the review of radical digital innovations from the market. Endogenous triggers, such as internal problems, constraints, and utilization of newly generated resources, are also critical. Thus, firms' need to develop capabilities to scan not only the external environment, but also their internal settings.

Our study has limitations. For example, interviewing customers could generate additional valuable insights into their role in contributing to realizing a transformed value creation system facilitating DT. Furthermore, at Lundqvist, entrepreneurial activities were initially mainly driven by management. How, and when, activities of key actors translate into collective organizational capabilities requires further analysis. We hope that the model can aid future investigations into the building of DC and their role in shaping DT.

\section{References}

[1] R. Amit and X. Han, "Value Creation through Novel Resource Configurations in a Digitally Enabled World," Strategic Entrepreneurship Journal, 2017, vol. 11, no. 3, pp. 228-242.

[2] R. Amit and C. Zott, "Creating Value Through Business Model Innovation," MIT Sloan Management Review, 2012, vol. 53, no. 3, p. 41-49.

[3] M. Beliveau, L. A. De Santa-Eulalia, E. Mosconi, and N. Cadieux "How Can SME Embark in a Digital Transformation in the Context of the 4th Industrial Revoution?" In 2nd International Symposium on Supply Chain 4.0, 2018, pp. 37-42.

[4] S. J. Berman, "Digital transformation: opportunities to create new business models," Strategy \& Leadership, 2012, vol. 40, no. 2, pp. 16-24.

[5] P. Besson and F. Rowe, "Strategizing information systems-enabled organizational transformation: A transdisciplinary review and new directions," The Journal of Strategic Information Systems, 2012, vol. 21, no. 2, pp. 103124.

[6] A. Bharadwaj, O. A. El Sawy, P. A. Pavlou, and N. Venkatraman, "Digital Business Strategy: Toward a Next Generation of Insights," MIS Quarterly, 2013, vol. 37, no. 2, pp. 471-482.

[7] R. J. Boland Jr, K. Lyytinen, and Y. Yoo, "Wakes of Innovation in Project Networks: The Case of Digital 3-D 
Representations in Architecture, Engineering, and Construction," Organization Science, 2007, vol. 18, no. 4, pp. 631-647.

[8] G. A. Bowen, "Grounded Theory and Sensitizing Concepts," International Journal of Qualitative Methods, 2006, vol. 5, no. 3, pp. 12-23.

[9] V. Braun and V. Clarke, "Using thematic analysis in psychology," Qualitative Research in Psychology, 2006, vol. 3, no. 2, pp. 77-101.

[10] Coltman, T., Tallon, P., Sharma, R., \& Queiroz, M. Strategic IT alignment: twenty-five years on. Journal of Information Technology, 2015, vol. 30, no. 2, pp. 91-100.

[11] A. Dubois and L. E. Gadde, "The construction industry as a loosely coupled system: implications for productivity and innovation," Construction Management and Economics, 2002, vol. 20, no. 7, pp. 621-631.

[12] K. M. Eisenhardt and J. A. Martin, "Dynamic capabilities: what are they?" Strategic Management Journal, 2000, vol. 21, no. 10-11, pp. 1105-1121.

[13] O. A. El Sawy, A. Malhotra, Y. Park, and P. A. Pavlou, "Research Commentary-Seeking the Configurations of Digital Ecodynamics: It Takes Three to Tango," Information Systems Research, 2010, vol. 21, no. 4, pp. 835-848.

[14] M. S. Feldman, and B. T. Pentland, "Reconceptualizing Organizational Routines as a Source of Flexibility and Change," Administrative Science Quarterly, 2003, vol. 48, no. 1, pp. 94-118.

[15] S. Gao, E. Hakanen, P. Töytäri, and R. Rajala, "Digital transformation in Asset-intensive Businesses: Lessons Learned from the Metals and mining Industry" Proceedings of the $52^{\text {th }}$ Hawaii International Conference on Systems Sciences, 2019, pp. 4927-4936.

[16] L. Heilig, S. Schwarze, and S. Voß, "An Analysis of Digital Transformation in the History and Future of Modern Ports," Proceedings of the 50 th Hawaii International Conference on Systems Sciences, 2017, pp.1341-1350.

[17] O. Henfridsson, J. Nandhakumar, H. Scarbrough, and N. Panourgias, "Recombination in the open-ended value landscape of digital innovation," Information and Organization, 2018, vol. 28, no. 2, pp. 89-100.

[18] B. Hinings, T. Gegenhuber, and R. Greenwood, "Digital innovation and transformation: An institutional perspective," Information and Organization, 2018, vol. 28, no. 1, pp. 5261.

[19] C. Kahre, D. Hoffmann, and F. Ahlemann, "Beyond Business-IT Alignment - Digital Business Strategies as a Paradigmatic Shift: A Review and Research Agenda," Proceedings of the $50^{\text {th }}$ Hawaii International Conference on Systems Sciences, 2017, pp. 4706-4715.

[20] L. Li, F. Su, W. Zhang, and J. Y. Mao, "Digital transformation by SME entrepreneurs: A capability perspective," Information System Journal, 2018, vol. 28, no. 6, pp. 1129-1157.

[21] C. Matt, T. Hess, and A. Benlian, "Digital Transformation Strategies," Business \& Information Systems Engineering, 2015, vol. 57, no. 5, pp. 339-343.

[22] S. Nambisan, K. Lyytinen, A. Majchrzak, and M. Song, "Digital Innovation Management: Reinventing Innovation Management Research in a Digital World," MIS Quarterly, 2017, vol. 41, no. 1, pp. 223-238.
[23] D. Nylén, and J. Holmström, "Digital innovation strategy: A framework for diagnosing and improving digital product and service innovation" Business Horizons, 2015, vol. 58 , no. 1 , pp.57-67.

[24] J. Sandberg, "Digital capability: investigating coevolution of IT and business strategies," Doctoral dissertation, Umea University, 2014.

[25] J. Sandberg, J. Holmström, and K. Lyytinen, "Digitization and Phase Transitions in Platform Organizing Logics: Evidence from the Process Automation Industry", MIS Quarterly Forthcoming.

[26] A. Shibeika, and C. Harty, "Diffusion of digital innovation in construction: a case study of a UK engineering firm," Construction Management and Economics, 2015, vol. 33, no. 5-6, pp. 453-466.

[27] D. A. Skog, "The Dynamics of Digital Transformation: The Role of Digital Innovation, Ecosystems and Logics in Fundamental Organizational Change," Diss. Umea University, 2019.

[28] D. J. Teece, "Explicating dynamic capabilities: the nature and microfoundations of (sustainable) enterprise performance," Strategic Management Journal, 2007, vol. 28, no. 13, pp. 1319-1350.

[29] D. J. Teece, "A dynamic capabilities-based entrepreneurial theory of the multinational enterprise," Journal of International Business Studies, 2014, vol. 45, no. 1, pp. 8-37.

[30] D. J. Teece, G. Pisano, and A. Shuen, "Dynamic capabilities and strategic management," Strategic Management Journal, 1997, vol. 18, no. 7, pp. 509-533.

[31] A. H. Van de Ven, and M. S. Poole, "Explaining Development and Change in Organizations," The Academy of Management Review, 1995, vol. 20, no. 3, pp. 510-540.

[32] N. Venkatraman. "IT-enabled Business Transformation: From Automatization to Business Scope Redefinition", Sloan Management Review, 1994, vol. 35, no. 2. p 73-87.

[33] G. Vial, "Understanding digital transformation: A review and a research agenda," The Journal of Strategic Information Systems, 2019, vol. 28, no. 2, pp. 118-144.

[34] K. Vogelsang, K. Liere-Netheler, S. Packmohr, and U. Hoppe, "Barriers to Digital Transformation in Manufacturing: Development of a Research Agenda," Proceedings of the 52nd Hawaii International Conference on System Sciences, 2019, pp. 4937-4946.

[35] G. Walsham, "Doing interpretative research", European Journal of Information Systems, 2006, vol. 15, no. 3, pp. 320330.

[36] P. Weill and S. L. Woerner, "Optimizing your digital business model," MIT Sloan Management Review, 2013, vol. 54, no. 3, pp. 71-78.

[37] A. Yeow, C. Soh, and R. Hansen, "Aligning with new digital strategy: A dynamic capabilities approach," The Journal of Strategic Information Systems, 2018, vol. 27, no. 1, pp. 43-58.

[38] R. K. Yin. "Case Study Research: Design and Methods", Sage, London, 2014.

[39] Y. Yoo, O. Henfridsson, and K. Lyytinen, "Research commentary-The New Organizing Logic of Digital Innovation: an Agenda for Information Systems Research," Information Systems Research, 2010, vol. 21, no. 4, pp. 724735 . 